\title{
Group size and composition of work groups as precursors of intragroup conflicts
}

This article was published in the following Dove Press journal:

Psychology Research and Behavior Management

\author{
Andrey $V$ Sidorenkov' \\ Evgueni F Borokhovski \\ Viktor A Kovalenko3 \\ 'Department of Psychology of \\ Management, Southern Federal \\ University, Rostov-on-Don, Russia; \\ ${ }^{2}$ Systematic Reviews Project \\ Manager of the Centre for the \\ Study of Learning and Performance \\ at Concordia University, Montreal, \\ Canada; ${ }^{3}$ Department of Finance, \\ Kombaynovy Rostselmash Plant, \\ Rostov-on-Don, Russia
}

Purpose: This study explores the connections between formal quantitative group characteristics (such as group size, group composition by gender, age, and duration of group membership of individual workers, their average age, and duration of membership) with three levels of conflict (ie, interpersonal, individual-group, and individual-subgroup) of two types (ie, activity-oriented and subject-oriented).

Method: Forty-one work groups - small-size enterprises and basic-level teams and units in medium-size companies and large corporations, with the total sample of 334 individual workers - took part in the study. The study employed the questionnaire of interpersonal conflicts in a group and the questionnaire of individual-group and micro-group conflicts as assessment tools. Subsequent regression analyses explored the relationships between group size and composition on one hand and types and levels of conflict on the other.

Results: The study established that group size is negatively associated with the individual-subgroup subject-oriented conflict. Also, group size moderates the connections between several formal group characteristics and conflict types and levels. These connections are detected in large-size groups but are nearly nonexistent in small-size groups. Group diversity by gender is negatively associated with the individual-group activity-oriented conflict (across all participating groups) and with the interpersonal and individual-group subject-oriented conflicts (in large-size groups only). Group composition by duration of group membership is negatively associated with the individual-subgroup subject-oriented conflict (across groups), participants' average age and duration of group membership - with both types of the individual-subgroup conflict. Out of all group characteristics under consideration, only group composition by age was not associated with either of the conflict parameters.

Discussion: The paper makes a special point out of the fact that group characteristics served as much stronger predictors for conflict parameters in large-size groups than either in smallsize groups or in the entire sample, indicating that the increase in group size strengthens the influence of group characteristics on conflict parameters.

Conclusion: The research findings indicate that it is important, when studying connections between group composition and conflicts within the group, to take group size and its influence on types and levels of the intragroup conflict into account.

Keywords: group composition, group size, intragroup conflict, conflict levels, conflict types

\section{Introduction}

Various intragroup conflicts (ie, interpersonal conflict, conflict between an individual group member and the entire group, etc) have been in the focus of attention of researchers in many fields including social, organizational, and military psychology; sociology; and management. This interest is rooted in the fact that conflicts affect all
Department of Psychology of

Management, Southern Federal

University, st. M. Nagibina, I3, Room

238, Rostov-on-Don, 344038, Russia

Tel +7 8632101178

Email av.sidorenkov@yandex.ru 
aspects of group activity, dynamics of relationships among group members, their attitudes toward collaborative and individual performance, and on their emotional state and satisfaction with group work. The issue of the genesis and dynamics of conflicts is among the most pressing in research on small group activity. Unveiling sources and mechanisms of intragroup conflicts is a key step toward our ability to anticipate conflict situation and suggests means for their meaningful resolution. It is especially important for so-called small work groups - small-size enterprises, structural units of the medium-size companies and large corporations, for example, administrative departments, teams of top managers, local crews, and narrow-in-scope taskforces at work places. In essence, they determine the efficiency and competitiveness of their respective organizations, as well as well-being and professional development of individual group members.

For a better understanding of intragroup conflicts, it is imperative to distinguish between conflict causes and precursors. Researchers often define the former as some form of contradictions. ${ }^{1-3}$ Specifically, some research has addressed the connections between different forms of contradictions and different levels of conflict, ${ }^{4}$ namely Interpersonal (ie, conflict between individual group members), Individual-Group (ie, between an individual and the group as a whole), IndividualSubgroup (ie, between an individual and a subgroup within the group), Subgroup-Subgroup (ie, between subgroups within the group), and Subgroup-Group (between a subgroup and the entire group).

On the other hand, conflict precursors include external and internal circumstances surrounding and shaping the reality in which the group functions. Among internal factors, researchers typically pay close attention to personal traits of group members and to formal characteristics of the group as a whole. For example, it was shown that women are predisposed to conflicts that are relevant to their personal needs, whereas for men, conflicts are directly related to their work activities. ${ }^{5}$ Also, the number of conflicts related to adaptation problems declines considerably with the increase in workers' age, when their behavior becomes more and more determined by orientation toward the group's goals. According to another research, ${ }^{6}$ the transformative behavior of the group leader showed a greater capacity for triggering various affective conflicts among the group members. Researchers also ascertained that team social cohesion was associated with different conflict styles: higher levels of cohesion were characteristic of groups predominantly using a constructive conflict style and less of a destructive conflict style. ${ }^{7}$ Trust among group members, as a moderator, lowered the probability of task conflicts escalating to relationship conflicts. ${ }^{8}$

Among determinants of the intragroup conflicts, researchers often consider formal quantifiable group characteristics such as group size and composition. For instance, a positive association between group size and both cognitive and emotional conflicts was discovered. ${ }^{9}$ In contrast, another study ${ }^{10}$ detected no significant connection between group size and task and relationship conflicts.

To clarify the terminology, cognitive conflict is related to the task in the focus of the group activity and involves differences in points of view, ideas, and opinions, whereas emotional conflict is based on the interpersonal incompatibility of the individual group members. ${ }^{6}$ The other category - relationship conflict - can be defined as a disagreement among group members with respect to subjective perception of their personal problems, preferences, and values. ${ }^{11}$ Finally, task conflict denotes mismatch in the group members' understanding of the task and their interpretation of taskrelated information, whereas the process conflict primarily represents disagreement about how the task implementation should be achieved in terms of labor division, resource allocation and management, and sharing and delegating duties and responsibilities. ${ }^{11}$

In the research literature, there are more prevalent studies that consider group composition with combinations of several characteristics. Some of these characteristics are easy to perceive (eg, gender or race), whereas other belong to more obscure criteria. Among those is how long individual workers have worked for the organization (ie, duration of membership in the group) or their professional qualifications. There are various examples of such empirical studies. ${ }^{12-15}$

It is possible to approach the issue of direct connections between group composition and conflict from three different angles. One focuses on studying the direct link between them, though the literature does not provide any substantive confirmation of that type of relationship. Some researchers do not see any connection between group diversity by age or gender and task and relationship conflicts, ${ }^{10,16}$ between group composition by personality traits of extraversion and introversion and perception of interpersonal conflict by group members, ${ }^{17}$ or between diversity-consistency by extraversion and relationship conflict. ${ }^{18}$ Nevertheless, studies conducted on student groups discovered that gender diversity is positively associated with relationship conflict. ${ }^{19}$ Also, diversity in values is positively associated with interpersonal conflict in general $^{20}$ and with task and relationship conflict. ${ }^{14,16}$ In addition, cultural diversity may lead to an escalation in task, 
process, and relationship conflicts. ${ }^{21}$ Likewise, diversity in education predicts task conflict, ${ }^{19}$ whereas diversity in duration of group membership may strengthen relationship conflict. ${ }^{22}$

Another approach emphasizes the moderating role of some variables in connection (indirect in that sense) between group composition and conflict. For example, it was described how gender identity salience served as a moderator variable in shaping connection between the (quantified) distinctiveness of group composition by gender and relationship conflict in working groups for men. ${ }^{23}$ One longitudinal study ${ }^{16}$ established that identification of the team moderated positive connection between value dissimilarity and relationship conflict at Time 1. Team identification was also implicated in the effects of group dissimilarity by gender, age, and ethnicity on task conflict, as well as the effect of professional dissimilarity on relationship conflict at Time 2 . Team orientation and team process both emerged as moderator variables for the link between group diversity and conflict. ${ }^{18}$ In particular, team orientation helped to neutralize the negative influence of group gender diversity on relationship conflict, whereas team processes weakened the damaging effects of group diversity by the (deep-level) criterion of "time urgency" on relationship conflict. It was reported that the length of group lifespan led to a reduction of the effects that duration of group membership had on relationship conflict. ${ }^{22}$

The third approach is to look at the role of group composition in affecting connection between some conflict characteristics and the conflict. Low diversity (by educational level, gender, race, age, and work history) moderate indirect positive influence of distributive injustice on task conflict. ${ }^{15}$

There is a general consensus that group diversity is one of the key precursors for intragroup conflict. Nevertheless, further investigation of specific connections between formal group characteristics and conflict in different contexts is necessary. In our view, among the most prospective research directions are those of links not only between group composition and interpersonal conflict, but also between an individual group member and the entire group (IndividualGroup conflict), between an individual and some informal subgroup (Individual-Subgroup conflict), between informal subgroups within the group (Subgroup-Subgroup conflict), or between an informal subgroup and the rest of the group (Subgroup-Group conflict). It is worth mentioning that informal subgroups can form within small groups of various types. Here we define informal subgroup as a cluster of group members joining together based on commonality/unity of one or several shared (meaningful and important for all of them) psychological characteristics that also distinguish them from the rest of the group. For example, in small work groups composed of 4-15 members, the number of informal subgroups may vary from one (or more typically from two) to four. ${ }^{3}$ Probabilistically speaking, dyads are more likely to emerge than triads, whereas the formation of subgroups composed of four to six is extremely rare. On average, more than half of the whole group members belong to such subgroups. Thus, it is only natural to envision the existence of conflicts between an individual group member and a subgroup, among subgroups or between a subgroup and a group as a whole. Moreover, conflicts at the level of subgroups may influence the entire group's functioning to a much greater extent than any interpersonal conflict. Besides, interpersonal conflicts between individual group members, who are also members of different informal subgroups, may grow into a conflict between these subgroups as other members tend to get pulled into it. There is also a possibility of transforming an interpersonal conflict into a conflict between an individual and the entire group if the group decides to support this person's opponent.

The conflicts of all these levels (eg, group or "individualgroup" and microgroup or "individual-subgroup"), as much as interpersonal conflicts, could be of different types and depend on the group size and composition. The direction and strength of such a dependency may substantially deviate from predominantly positive associations between interpersonal conflict and the abovementioned group characteristics observed in previous research.

Unfortunately, too few empirical studies have paid attention to average age of group members and the duration of their group membership (ie, within group work experience) as factors that influence conflict genesis and manifestations. The research on group size as a variable that may substantially affect the links between group composition and the conflict is practically nonexistent, although group size (and possibly other variables) may likely play a role. In fact, there is no sound research on group size as a moderator variable in the connection between group composition and intragroup conflict, whereas in our view, the parameters of this connection may be different in small-size and large-size work groups.

\section{Framework}

We define conflict as a form of disintegrative interactions/ relationships among actors (individuals or/and groups and subgroups), which is triggered by an acute intensification in contradictions and manifests itself in the actors' actively negative perceptions of and actions toward each other. 
Framework of the current study is based on a bi-dimensional model (Figure 1) that has been recently developed. ${ }^{4}$ The model distinguishes between dimensions of conflict levels and conflict types. Specifically, conflict levels are 1) interpersonal (ie, between individual group members); 2) "individual-subgroups" (sometimes also referred to as micro-group conflict); 3) "individual-group" (ie, between an individual group member and the entire group); 4) "intersubgroup" or "subgroup-subgroup" (ie, between subgroups within the same group); and 5) "subgroup-group" (ie, between a subgroup and the entire group).

Conflict at each level can be of two types: 1) activityoriented conflict (AOC) and 2) subject-oriented conflict (SOC). The major criterion distinguishing the two is the corresponding area of group activity - either instrumental (directly linked to any task-related joint activities) or social (interpersonal contacts and relationships outside of taskrelated activities). Thus, AOC can be described as a conflict in which confrontation (actively negative perception and deeds) between/among its sides is rooted in task-related group activities such as understanding of task requirements and solution options, goal-setting, decision-making, or assignment of roles and responsibilities. AOC, in fact, includes both task and process conflicts. On the other hand, SOC encompasses negative perceptions and confrontational actions that are not directly connected to task-related behaviors. SOC does not stem from the professional or business-aligned characteristics of the sides involved in a conflict but is rooted in their subjective qualities such as personal traits, norms and values of the individuals, subgroups and the entire group, conflict participants' behavioral patterns, and so on.

As stated earlier, the most prevalent conflict types, the research literature considers, include conflicts of relationships, task, and process. ${ }^{11,24-27}$ Our model uses a somewhat different approach that focuses on the other set of constructs. The reasons for that are as follows.

First, the phenomenon of interpersonal conflict in general and its specific forms are often understood as disagreements between/among sides involved in a conflict. However, it is obvious to us that disagreements may be a necessary, albeit insufficient, condition for conflict. Parties can have differences of opinion and openly express them or argue over them, but this may not necessarily result in what would qualify as a conflict.

Second, in the process of developing and validating the Russian version of a questionnaire for studying interpersonal group conflicts, the idea of just two types of working conflicts (namely task and process conflicts) received no empirical confirmation. ${ }^{28}$ In addition, some researchers remarked on the challenges in distinguishing between these two conflict types conceptually, ${ }^{29}$ while acknowledging the relatively high correlation between the measures of task and process conflicts - there are various examples of that. ${ }^{26,27,30}$ Consequently, we see the need for more refined (nuanced and reliable) approaches to assessing task and process conflicts that are capable of detecting and reflecting the uniqueness of each.

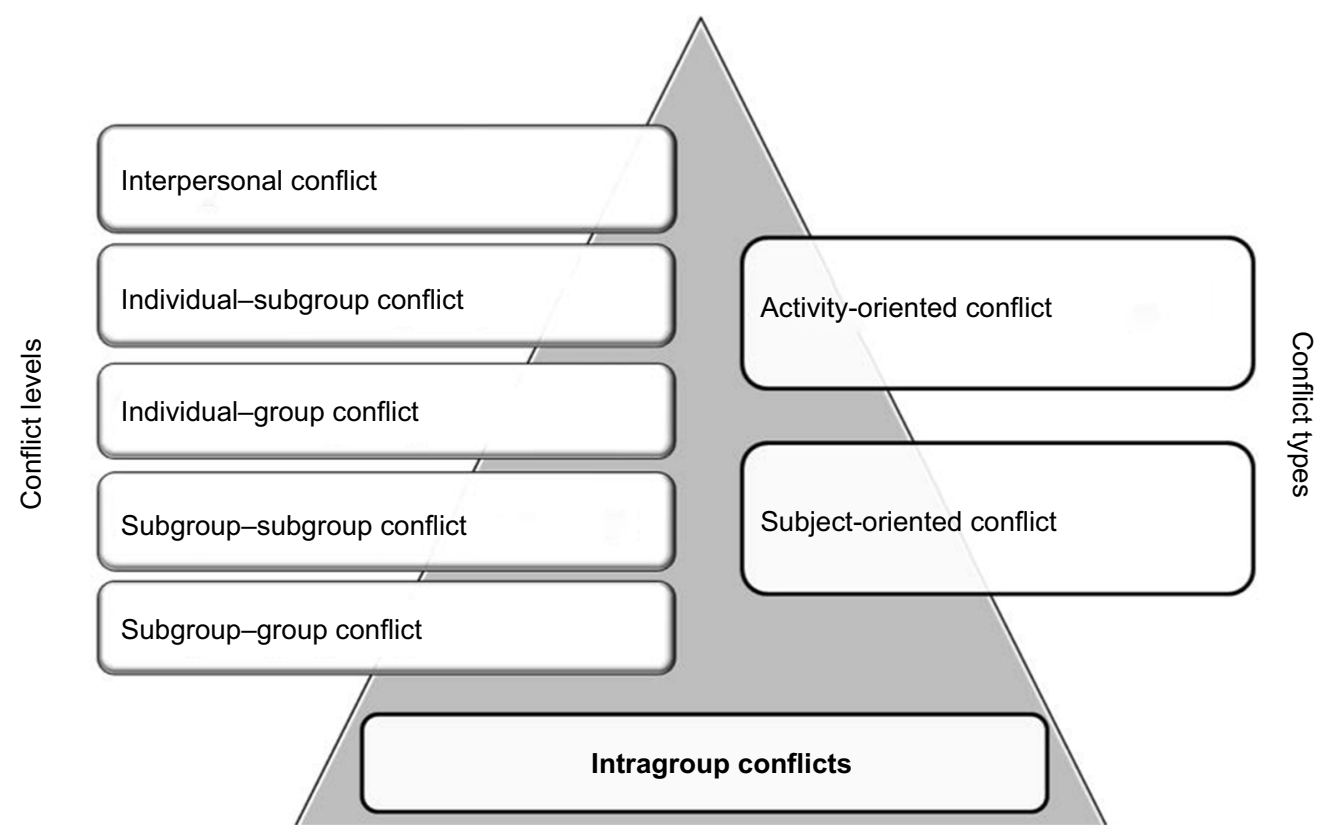

Figure I Types and levels of intragroup conflict. 
Finally, SOCs in many aspects resemble what is typically described as relationship conflict. After all, any known conflict (relationship, task, or process) has a relationship component - as much as it involves at least two parties (sides of the conflict) and interactions between/among them. As a result, the term "relationship conflict" seems to be too broad, spreading far beyond its intended field of application.

One of the earlier studies, ${ }^{4}$ while exploring the factorial structure of intragroup conflict in its connections with the effectiveness of group activity, also strongly advocated the idea of multilevel structure of intragroup conflict. Like in that previous study, due to the restrictions in scope of the available assessment instruments, here we focus on the analyses of three (out of five conceptualized) conflict levels (interpersonal, micro-group, and group) of two types (activity-oriented and subject-oriented).

The main objective of this study was to detect and describe connections between the above-mentioned formal group characteristics and the types and levels of intragroup conflicts. Specifically we addressed the following research hypotheses: 1) Group size is positively associated with interpersonal and "individual-group" conflicts and negatively associated with "individual-subgroup" conflict; 2) Heterogeneity of group composition by age, gender, and experience (i.e., duration of work with the group) is negatively connected to interpersonal and "individual-group" conflicts. In other words, groups that are more heterogeneous with respect to age, gender, and working experience are prone to generate (manifest) fewer (less intensive) interpersonal and "individual-group" conflicts; 3) Average age of individual group members and average duration of their group membership have negative associations with "individual-group" and "individual-subgroup" conflicts; and 4) Connections between group characteristics (namely age, gender, and experiencebased composition, as well as individuals' average age and duration of group membership), on one side, and types and levels of conflict, on the other, depend on group size. More specifically, these connections are quite evident in large-size groups and nearly nonexistent in small-size groups.

\section{Methods}

\section{Participants}

Forty-one intact work groups took part in our investigation. These were small-size enterprises and low-level divisions of middle-size and large companies and organizations (eg, administrative departments, teams of managers, shifts in restaurant and customer services, local crews, and narrow- in-scope taskforces at work places) - all residing in Russian Federation. Different types of industries were represented in the sample, including retail, customer and social services, banking and financial services, design, and manufacturing. Group size ranged from 4 to 21, with the average of eight members in a group. The total sample counted 334 of participants, or $94 \%$ of the entire number of individuals on payroll of the work groups included in our research, $62.2 \%$ of whom were women and $37.8 \%$ men. Participants' age ranged from 19 to 70 years ( mean $=30$ years, median $=35$ years), with a wide variation in membership duration from 1 to 300 months ( mean $=71.5$ months, median $=48$ months).

Recruitment of participants and assessment administration unfolded in compliance with the ethical regulations and standards of the Russian Psychological Association (http:// рпо.pф) as outlined in: http://pпo.pф/rpo/documentation/ ethics.php.

\section{Instruments}

The study employed Russian versions of two questionnaires for assessing intragroup conflicts, as follows.

\section{Questionnaire of interpersonal conflicts in a group}

This questionnaire has been constructed to study AOC or also referred to as job conflict and SOC in a small group. ${ }^{28}$ The stimulus material of the questionnaire had eight items - four in each of the two subscales: AOC-Inter-P and SOC-Inter-P (eg, "In the joint performance of their duties, the colleagues often reproach and criticize one another," "Personal relations among the colleagues are often marred by discontent and bad temper"). Evaluation by the subjects of the severity of the attribute reflected by each item is on the basis of a 7-point scale (from completely agree $=1$ to completely disagree $=7$ ). The Cronbach's alpha values were 0.89 (AOC) and 0.90 (SOC). Principle component factor analysis (promax rotation) discovered two factors composed of items with the factor load from 0.752 to 0.977 (AOC) and from 0.626 to 0.978 (SOC), respectively. These factors were correlated at 0.68 . Average expert ratings (on a 5-point scale) varied from 4.00 to 4.66 for the item content validity and from 4.70 to 4.90 for the item apparent validity.

\section{Questionnaire of individual-group and individual- subgroup conflicts}

This questionnaire measures these two levels of conflict for the activity-oriented (AOC-IG and AOC-IS) and subjectoriented (SOC-IG and SOC-IS) conflict types. ${ }^{31}$ It contains two scales that address individual-group and individual- 
subgroup levels of conflicts, respectively. There are four items per scale (eg, "Individual group members are often annoyed by the group tendency to ignore their professional opinions" or "The group as a whole is often hostile toward its individual members even when they are professionally competent and reliable"). Response options are arranged alongside a 7-point Likert-wise scale. The Cronbach's alpha values for the subscales were 0.91 (AOC-IG) and 0.96 (SOC-IG). Two-factor solution for the individualgroup conflict type resulted in the following factor loads: $0.801-0.927$ for items of the AOC subscale and 0.920-0.954 for items of the SOC subscale with the cross-factor correlation of 0.63 . Indices of content and apparent item validity ranged from 4.66 to 5.00 for the former and from 4.46 to 5.00 for the latter.

The current study limits its interest to two types at three levels of intragroup conflict, as described above, according to the scope (three out of conceptually defined five conflict levels) of the instruments employed.

\section{Ethical consideration}

This research, in its part of dealing with human participants, followed guidelines and ethical standards of the Russian Psychological Association: http://pпо.pф/rpo/documentation/ ethics.php. The study implementation plan was discussed and approved by the expert committee "Psychology and Pedagogy" of the Southern Federal University (Rostov-onDon, Russia). Before entering the study, all participants were informed of its purposes and then signed a standard consent form to confirm their willingness to take part in the study.

\section{Procedure}

Both the questionnaires were a part of the computer-based assessment system “Group Profile" (GP) recently developed ${ }^{32}$ and then modified in 2016 (GP-M16) for the purposes of increasing its capacity for data analyses. The participants were surveyed individually on personal computers (equipped with GP-M16, which maintained control over the standardized data collection protocol. The program could suspend accepting participants' input in case of frequent omissions and/or apparently biased responses. GP-M16 also implemented first-level data analysis, thus ensuring high consistency and reliability of data collection processes.

In addition, the study participants were required to selfreport the following information: gender, age (whole number of years), and duration of their group membership (expressed as a number of months). These data were subsequently verified by comparing them with the official records provided by the departments of human resources of their respective organizations.

\section{Formal group characteristics}

This study relies on the following formal quantifiable group characteristics: group size, its composition by age, gender, and experience of individual members, as well as their average age and duration of group membership.

For the assessment of group composition (ie, the estimate of its heterogeneity/homogeneity) by the criteria of participants' age and duration of group membership, we used variation coefficient $(V)$, calculated as follows:

$$
V=\frac{\sigma}{\bar{x}} * 100
$$

where $\sigma$ is the standard deviation and $\bar{x}$ is the mean of the corresponding measure (eg, age) for the sample.

The variation coefficient applies only to criteria that are measured quantitatively on a continuous scale, and its larger value reflects higher degree of group diversity (heterogeneity).

However, composition by gender (a categorical variable) cannot be assessed for diversity by the variation coefficient. Instead, the Blau index of heterogeneity was calculated: ${ }^{33}$

$$
D=1-\sum P_{1}^{2}
$$

where $P$ is the category-specific proportion of group members and $i$ is the number of categories under consideration. Blau index is primarily used in research studies that deal with assessing group composition by gender or any other categorical criterion. ${ }^{18,34}$

Specifically in case of gender, this index may range from 0 , representing absolute homogeneity (all group members are of the same gender or proportion of $0 / 100$ ) of -0.5 , indicating maximum diversity (equal number of group members of each gender or proportion of 50/50). Also, we calculated average values for age and duration of group membership of each participating group.

\section{Conflict types and levels}

Data analysis with regard to classification of conflict types and levels, as well as the identification of informal subgroups within participating work groups was implemented by means of the computer package GP-M16.

\section{Connection of group size with types and levels of intragroup conflict}

Linear regression analysis was employed to assess the degree of association of each of the group formal characteristics 
(group size and variables depicting various parameters of group composition - as independent predictors) with types and levels of intragroup conflict (as the criterion variables). To derive the taxonomic group classification, we used hierarchical agglomerative cluster analysis (the square Euclidean distance algorithm determined distances between clusters). This method was essential for establishing quantitative boundaries between small-size and large-size groups in our investigation. Nonparametric binomial criterion was used to statistically assess the likelihood of differential representation of these two types of group size in the established clusters. As a result, this analysis allowed us to approach the task of studying connections between group formal characteristics and conflict parameters separately for small-size and largesize groups.

Both regression and cluster analyses were performed within the SPSS 17.0 software package.

\section{Results}

To address the objectives of the current study, we explored the entire array of connections between quantifiable formal group characteristics and conflict parameters (types and levels of conflict). Accordingly, our presentation of the study findings is organized around specific patterns of results as follows.

\section{Informal subgroups within a group}

We specifically distinguish microgroup (ie, individual-subgroup) conflict from both interpersonal conflict and group (ie, individual-group) conflict and hypothesize that its parameters may depend on some formal group characteristics, such as group size and particular aspects of group composition as outlined in research hypotheses 1-3. Therefore, it was imperative to make sure that the participating groups comprised informal subgroups.

The study detected the presence of informal subgroups in all participating groups. There were 69 such subgroups in total, varying from one to four within one group. Two hundred and twelve workers $(65.6 \%$ of the total number of the study participants) were members of these subgroups. Proportion of workers involved in informal subgroups ranged across participating groups from $14.5 \%$ to $100 \%$. The most frequent were dyads (39.9\%), followed by triads (30.4\%), whereas other subgroup sizes were much less prevalent: $17.4 \%$ of subgroups were composed of four members, $10.2 \%$ of five members, and $2.9 \%$ of six members. Keeping this level of diversity in mind, we hypothesized that 1) there is a high probability of the emergence of individual-subgroup conflicts; and 2) formal quantitative group characteristics may be linked to individual-subgroup conflicts.

\section{Connection between formal quantitative characteristics of work groups and conflict parameters}

Research hypothesis 1 suggested that group size positively predicts interpersonal and individual-group, whereas it is negatively associated with individual-subgroup conflict. We conducted regression analysis on data collected from the entire sample of participating work groups. Its results (Table 1) show that group size is negatively connected with SOC-IS

Table I Results of regression analysis of associations between formal quantitative group characteristics (independent variables) and conflict types and levels (dependent variables)

\begin{tabular}{|c|c|c|c|c|c|c|c|}
\hline \multirow[t]{2}{*}{ Group characteristics } & \multirow{2}{*}{$\begin{array}{l}\text { Model } \\
\text { statistics }\end{array}$} & \multicolumn{6}{|l|}{ Conflict } \\
\hline & & $\begin{array}{l}\text { AOC- } \\
\text { Inter-P }\end{array}$ & $\begin{array}{l}\text { SOC- } \\
\text { Inter-P }\end{array}$ & AOC-IS & SOC-IS & AOC-IG & SOC-IG \\
\hline \multirow[t]{2}{*}{ Size } & $\beta$ & 0.12 & 0.04 & -0.28 & $-0.42^{* *}$ & 0.23 & 0.09 \\
\hline & $R^{2}$ & 0.01 & 0.00 & 0.08 & 0.18 & 0.05 & 0.00 \\
\hline \multirow[t]{2}{*}{ Gender composition } & $\beta$ & 0.02 & -0.18 & 0.17 & 0.22 & $-0.32^{*}$ & -0.19 \\
\hline & $R^{2}$ & 0.00 & 0.03 & 0.03 & 0.05 & 0.10 & 0.03 \\
\hline \multirow[t]{2}{*}{ Age composition } & $\beta$ & -0.03 & 0.06 & -0.06 & -0.15 & -0.09 & 0.01 \\
\hline & $R^{2}$ & 0.00 & 0.00 & 0.00 & 0.02 & 0.00 & 0.00 \\
\hline Composition by duration & $\beta$ & 0.13 & 0.16 & -0.26 & $-0.33^{*}$ & 0.13 & -0.03 \\
\hline of group membership & $R^{2}$ & 0.02 & 0.03 & 0.07 & 0.11 & 0.02 & 0.00 \\
\hline \multirow[t]{2}{*}{ Average age } & $\beta$ & 0.10 & 0.13 & $-0.43^{* *}$ & $-0.34^{*}$ & 0.12 & 0.24 \\
\hline & $R^{2}$ & 0.01 & 0.02 & 0.19 & 0.11 & 0.01 & 0.05 \\
\hline Average duration of & $\beta$ & 0.14 & 0.12 & $-0.45^{* *}$ & -0.30 & 0.01 & 0.10 \\
\hline group membership & $R^{2}$ & 0.02 & 0.01 & 0.20 & 0.09 & 0.00 & 0.01 \\
\hline
\end{tabular}

Notes: $* * P<.01, * P<.05$

Abbreviations: AOC-Inter-P, interpersonal activity-oriented conflict; SOC-Inter-P, interpersonal subject-oriented conflict; AOC-IS , individual-subgroup activity-oriented conflict; SOC-IS, individual-subgroup subject-oriented conflict; AOC-IG, individual-group activity-oriented conflict; SOC-IG, individual-group subject-oriented conflict. 
( $\beta=-0.42, P<0.01$ ). In other words, the first hypothesis was not entirely supported as the negative connection of the group size and individual-subgroup conflict found its confirmation for one conflict type, but no positive connection between group size and interpersonal or individual-group conflict was detected.

In addition, we expected that group heterogeneity by gender, age, and duration of group membership is negatively associated with interpersonal and individual-group conflicts (research hypothesis 2), as well average age of group members and their work experience are negatively associated with individual-group and individual-subgroup conflicts (research hypothesis 3). We found that gender heterogeneity in significantly negatively associated with the AOC-IG $(\beta=-0.32, P<0.05)$. Heterogeneity in duration of group membership is negatively associated with the SOCIS ( $\beta=-.033, P<0.05)$, as well as average duration of group membership with the AOC-IS $(\beta=-0.45, P \leq 0.01)$. Similarly, average age of participants is negatively associated with both AOC-IS $(\beta=-0.43, P<0.01)$ and SOC-IS $(\beta=-0.34, P<0.05)$. Age diversity does not significantly affect any of the conflict parameters.

Thus, hypothesis 2 received only partial confirmation with regard to associations: "gender composition - individual-group conflict" and "composition by duration of group membership - individual-subgroup conflict" - across all participating groups. In turn, our findings supported hypothesis 3 in parts related to associations: "average age individual-subgroup conflict" and "average duration of group membership - individual-subgroup conflict.”

We considered a possibility that the participating groups might not be similar in their conflict parameters (ie, types and levels). Among possible reasons for that is the group size. If so, connections between group composition by age, gender, and duration of membership, as well as average age and average duration of group membership, on one hand, and conflict parameters, on the other, could be moderated by group size (research hypothesis 4). For the purposes of identifying groups that were more homogeneous in conflict structure, we conducted their taxonomic classification.

\section{Taxonomic group classification}

Hierarchical agglomerative cluster analysis revealed two taxonomic group types. The first was composed of 17 groups of which eleven groups had eight and over members $(64.7 \%$ of groups within this cluster), five counted five members (29.4\%), and one group (5.9\%) had six members. The second taxonomic type comprised 24 groups, 20 of them (83.3\% in this cluster) had seven members and lower, whereas the other four were composed of eight, nine, ten, and eleven members each.

Nonparametrical binomial criterion was used to assess statistical probability that in the first cluster larger groups (with more than eight members) are reliably more prevalent than smaller ones (seven and fewer members), and vice versa, the second cluster consists of higher number of small and lower number of large groups. The results of this analysis are presented in Table 2 .

As shown in the table, within the first cluster (labeled "larger groups"), the prevalence of groups with eight and more members over the groups with seven and fewer members was not statistically significant $(P>0.05)$. However, within the second cluster ("smaller groups"), groups with seven and less members were represented significantly more often than groups with eight and more members $(P<0.05)$. These results, at least, partly are indicative that conflict factorial structure may depend on the group size. Also, they allowed considering group size in seven members to be a boundary that separates large and small groups for the purposes of further analyses of specific (for each size type) intragroup conflicts manifestations.

Hence, based on the results of taxonomic classification, the entire sample of participating groups was split into two uneven in size categories: 1) small-size groups composed of seven and fewer workers ( $\mathrm{N}=27$ ) and 2) large-size groups that counted eight and more members $(\mathrm{N}=14)$.

\section{Connection between formal quantitative group characteristics and conflict parameters in groups different in size}

According to research hypothesis 4, connections between characteristics of group composition and average characteristics of its members, on one hand, and parameters of intragroup conflict (types and levels), on the other, depend on group size. In other words, formal group characteristics can serve as predictors of conflict parameters, especially

Table 2 Comparative results of empirically observed and expected group type distribution by the group size criterion

\begin{tabular}{|l|l|l|l|}
\hline $\begin{array}{l}\text { Taxonomic } \\
\text { type }\end{array}$ & Group type & $\begin{array}{l}\text { Empirically } \\
\text { observed } \\
\text { frequencies }\end{array}$ & $\begin{array}{l}\text { Criterion } \\
\text { critical } \\
\text { value }\end{array}$ \\
\hline \multirow{2}{*}{ Large-size } & Large-size groups & $\mathrm{II}$ & $\mathrm{X} \geq 13$ \\
& Small-size groups & 6 & $\mathrm{P}>0.05$ \\
\hline \multirow{2}{*}{ Small-size } & Small-size groups & 20 & $\mathrm{x} \geq 16$ \\
& Large-size groups & 4 & $P<0.05$ \\
\hline
\end{tabular}


in large-size groups, but may not be connected to conflict parameters in small-size groups. Regression analysis with the same set of independent and dependent variables, as the one described earlier, was now performed separately for large-size and small-size groups. The results are summarized in Tables 3 and 4. Table 3 shows that none of the associations between formal quantitative group characteristics and conflict parameters in small-size groups came to the level of statistical significance. At the same time, in large-size groups the following statistically significant results were observed: 1) negative association between group composition by gender and both SOC-Inter-P $(\beta=-0.69, P<0.01)$ and SOC-IG ( $\beta=-0.66, P<0.01) ; 2$ ) negative association between average age of group members and average duration of their group membership, on one hand, and AOC-IS ( $\beta=-0.78, P<0.001$ and $\beta=-0.72, P<0.001$, respectively), as well as with SOC-IS ( $\beta=-0.078, P<0.001$ and $\beta=-0.80, P<0.001$, respectively). It is possible then to suggest the whole array of regularities in connections between group characteristics and conflict parameters. The higher the group gender diversity is, the lower the SOC-Inter-P and SOC-IS are. The older, on average, the group members are, the weaker AOC-IS and SOCIS manifest themselves. Finally, the longer, on average, the group members participate in a group activity, the lower the degree of both AOC-IS and SOC-IS.

To summarize, research hypothesis 4 of the study was confirmed, but not for all characteristics of the large-size groups. Specifically, three out of five formal quantitative group characteristics under considerations demonstrated statistically significant associations with several conflict parameters in large-size groups, whereas no statistically significant connection of heterogeneity of group composition by age and duration of group membership with either of conflict parameter were detected. On contrary, no statistically significant correlations between quantifiable formal group characteristics and conflict parameters were detected in small-size groups, which in turn only supports research hypothesis 4 .

\section{Discussion}

As our findings indicate, group size is negatively connected to SOC-IS only. We suggest it might be explained as follows. In large-size groups, in contrast to small-size groups, the number of informal subgroups increases, and subsequently so does the complexity of relationships among them. Under these circumstances, each subgroup, in order to successfully interact with other subgroups and with the entire group, must preserve and maintain its unity. To achieve that kind of unity, behaviors of individual workers in such subgroups have to be more cautious and balanced, organized in a way that would prevent them from entering conflicts with their own subgroup. This cautious attitude may extend beyond one subgroup toward other subgroups, as a preventive measure against transforming individual-subgroup into conflict between subgroups, which would detrimental for the entire group functioning and, in turn, reflect badly on the subgroup, which these individual workers belong to. These considerations, when realized by individual members of an informal subgroup, lead to reduction of individual-subgroup conflict, especially when it is not related to the professional activity. However, when disagreements arise with respect to work, they may grow into individual-subgroup (task-oriented) conflict.

Our study also discovered negative connections between heterogeneity of group composition by gender and individual-group conflict (across the entire sample and in the

Table 3 Results of regression analysis of associations between formal quantitative group characteristics (independent variables) and conflict types and levels (dependent variables) in small-size groups

\begin{tabular}{|c|c|c|c|c|c|c|c|}
\hline \multirow[t]{2}{*}{ Group characteristics } & \multirow{2}{*}{$\begin{array}{l}\text { Model } \\
\text { statistics }\end{array}$} & \multicolumn{6}{|l|}{ Conflict } \\
\hline & & $\begin{array}{l}\text { AOC- } \\
\text { Inter-P }\end{array}$ & $\begin{array}{l}\text { SOC- } \\
\text { Inter-P }\end{array}$ & AOC-IS & SOC-IS & AOC-IG & SOC-IG \\
\hline \multirow[t]{2}{*}{ Gender composition } & $\beta$ & 0.18 & 0.02 & 0.17 & 0.21 & -0.23 & 0.01 \\
\hline & $R^{2}$ & 0.03 & 0.00 & 0.03 & 0.05 & 0.05 & 0.00 \\
\hline \multirow[t]{2}{*}{ Age composition } & $\beta$ & -0.14 & -0.01 & 0.00 & -0.01 & -0.20 & -0.01 \\
\hline & $R^{2}$ & 0.02 & 0.00 & 0.00 & 0.00 & 0.04 & 0.00 \\
\hline Composition by duration & $\beta$ & 0.03 & 0.04 & -0.35 & -0.34 & -0.04 & -0.15 \\
\hline of group membership & $R^{2}$ & 0.00 & 0.00 & 0.12 & 0.11 & 0.00 & 0.02 \\
\hline \multirow[t]{2}{*}{ Average age } & $\beta$ & 0.04 & 0.15 & -0.21 & -0.18 & 0.04 & 0.13 \\
\hline & $R^{2}$ & 0.00 & 0.02 & 0.04 & 0.03 & 0.00 & 0.02 \\
\hline \multirow{2}{*}{$\begin{array}{l}\text { Average duration of } \\
\text { group membership }\end{array}$} & $\beta$ & 0.29 & 0.29 & -0.26 & -0.16 & 0.11 & 0.14 \\
\hline & $R^{2}$ & 0.09 & 0.08 & 0.06 & 0.03 & 0.01 & 0.02 \\
\hline
\end{tabular}

Abbreviations: AOC-Inter-P, interpersonal activity-oriented conflict; SOC-Inter-P, interpersonal subject-oriented conflict; AOC-IS , individual-subgroup activity-oriented conflict; SOC-IS, individual-subgroup subject-oriented conflict; AOC-IG, individual-group activity-oriented conflict; SOC-IG, individual-group subject-oriented conflict. 
Table 4 Results of regression analysis of associations between formal quantitative group characteristics (independent variables) and conflict types and levels (dependent variables) in large-size groups

\begin{tabular}{|l|l|l|l|l|l|l|l|}
\hline Group characteristics & \multirow{2}{*}{$\begin{array}{l}\text { Model } \\
\text { statistics }\end{array}$} & \multicolumn{5}{|c|}{ Conflict } \\
\cline { 2 - 7 } & & $\begin{array}{l}\text { AOC- } \\
\text { Inter-P }\end{array}$ & $\begin{array}{l}\text { SOC- } \\
\text { Inter-P }\end{array}$ & AOC-IS & SOC-IS & AOC-IG & SOC-IG \\
\hline Gender composition & $\beta$ & -0.36 & $-0.69 * *$ & 0.07 & -0.07 & -0.43 & $-0.66^{* *}$ \\
Age composition & $R^{2}$ & 0.13 & 0.48 & 0.00 & 0.00 & 0.19 & 0.44 \\
& $\beta$ & -0.29 & -0.14 & 0.00 & 0.06 & -0.32 & -0.11 \\
Composition by duration & $R^{2}$ & 0.08 & 0.02 & 0.00 & 0.00 & 0.10 & 0.01 \\
of group membership & $\beta$ & -0.03 & 0.05 & 0.12 & 0.33 & 0.29 & 0.16 \\
Average age & $R^{2}$ & 0.00 & 0.00 & 0.01 & 0.11 & 0.08 & 0.03 \\
& $\beta$ & 0.07 & 0.21 & $-0.78^{* * *}$ & $-0.78^{* * *}$ & -0.05 & 0.37 \\
Average duration of & $R^{2}$ & 0.00 & 0.04 & 0.62 & 0.61 & 0.00 & 0.14 \\
group membership & $\beta$ & -0.31 & -0.25 & $-0.72^{* *}$ & $-0.80^{* * *}$ & -0.41 & -0.07 \\
\hline
\end{tabular}

Notes: $* * * P<0.001, * * P<0.01$.

Abbreviations: AOC-Inter-P, interpersonal activity-oriented conflict; SOC-Inter-P, interpersonal subject-oriented conflict; AOC-IS , individual-subgroup activity-oriented conflict; SOC-IS, individual-subgroup subject-oriented conflict; AOC-IG, individual-group activity-oriented conflict; SOC-IG, individual-group subject-oriented conflict.

large-size groups), as well as with interpersonal conflict (in large-size groups only). In the latter case, our results do not agree with the previous research, where no such connection was reported ${ }^{10,16}$ or some positive association between group gender diversity and interpersonal task and relationship conflicts emerged. ${ }^{19}$ It is possible that this discrepancy in findings resulted from some additional differences in groups that participated in different studies and from diversity of assessment instruments employed in these studies. Another factor that might lead to variations in findings is that the majority of studies undertaken previously did not take into account the group size variable. Findings of the current study with respect to group gender diversity make sense when it is considered that completely homogeneous groups (male of female workers only) members feel more freedom in building interpersonal relationships including the option with higher probability to create and participate in conflicts. On contrary, gender-wise more diverse groups could be characterized by the tendency of their members to exercise tighter control over their relationships with colleagues, to be more accurate in expressing opinions and passing judgement, to be more polite and politically correct, especially with those of the opposite gender. In other words, what would be considered quite appropriate in gender-homogeneous working environments appears to be unacceptable in interactions in cross-gender relationships. As such increase in gender heterogeneity (especially, in large-size groups) may lead group members to take special efforts to avoid conflicts with their colleagues and the entire group or to mitigate conflict manifestations considerably.

Negative dependence of SOC-IS from higher group heterogeneity by duration of group membership (detected across all participating groups), most likely, is due to the presence in such groups of both, "veterans" and "novices," types of workers, so that in a conflict-prone situations, the latter ("younger" and less experienced workers) tend to behave more carefully and be less critical toward those subgroups that include "older" (in terms of the longer group membership and more experienced) colleagues. In turn, subgroups with higher prevalence of the "veteran" workers could be more tolerant and forgiving toward less experienced colleagues, which also may lead to conflict prevention or mitigation.

Also, negative dependence of both types of individualsubgroup conflict from the average age of group members may be rooted in the general tendency for older people to behave more adaptively, to build their relationships with greater flexibility, especially with their closest circle of colleagues and friend, with whom they communicate most frequently. As a result, older group members tend to minimize conflicts within or with their own subgroup or any other group they would consider a referent subgroup.

There is another tendency, observed in our study that is toward lower individual-subgroup conflict depending on higher average duration of group membership. A reason for that could simply be that with longer working experience within the same group, its members develop business and interpersonal skills, instrumental for collegial problemsolving. Subsequently, the number of occasions potentially leading to conflict initiation and intensification are reduced - whether for conflicts between an individual worker and its own subgroup or other subgroup referent for this person in any respect. This kind of competencies are formed more rapidly and are more profound when individuals interact within the same subgroup than in interactions between members of 
different subgroups or among "independent" (ie, not included in a particular subgroup) group members or between "independent" workers and the entire group.

In large-size groups, statistically significant associations exist between three formal quantitative group characteristics (ie, group composition by gender, average age of group members, and average duration of their group membership) and various conflict parameters (types and levels of conflict), whereas in small-size groups, no statistically significant association between variables under consideration was detected. It means that group size serves as an intermediary variable in determining the strength and kind of relationships between group characteristics and conflict parameters. The higher the group size, the more salient role the abovementioned group characteristics in specifics of conflict manifestation.

\section{Limitations and future directions}

In the current study, we did not address the connections of quantifiable formal group characteristics with the following two levels of intragroup conflict: between informal subgroups and between a subgroup and the entire group. The reason for that is the limited scope of the existing assessment instrumentation that does not have capacity to target these two levels of intragroup conflict. As a result, the complete picture of association between group characteristics and conflict parameters (as it was depicted, for example, in Figure 1) is yet to be achieved. On the other hand, the list of compositional group characteristics, considered in the study, was not exhaustive. While we analyzed group composition by age, gender, and experience of individual members, as well as average age and duration of group membership, other potential predictors of intragroup conflict parameters (eg, group composition - that is homogeneity/heterogeneity - by educational level, professional knowledge and skills, ethnicity, abilities, personal traits, and believes of individual group members) were outside the scope of the current study. Further research should pay attention to studying connections between group characteristics and other conflict qualities including conflict sources (eg, difference in opinions, controversies between sides eventually involved in conflict) and conflict predispositions (eg, group cohesion, behavioral norms, group members' identities). It is important because all these, and possibly other, essential variables impose their influence on conflict parameters not only in isolation (independently) but also (and more critically) in complex interactions.

The conflict model, offered and partly substantiated in the current study, allows researchers to consider interpersonal conflict not just in general, but in the context of socio- psychological structure of a work group. Specifically, it is important to address sources and precursors of conflict and specific processes in which it unfolds - as in the context of group functioning, they will be different for conflicts between members of various informal subgroups and between members of the same subgroup. Subsequently, their connections to formal quantitative group characteristics should differ either. Moreover, researchers need to take into account both the forms of interpersonal conflict: personified and depersonified. The former is based on incompatibility of individual interests, values, attitudes, and personal antipathy (ie, "I am in conflict with this person because I dislike him/her..."). The foundation of the latter, however, rests either with the conflict of the informal subgroup, of which the conflict subject is a member, toward an individual on the other side of the conflict (ie, individual-subgroup conflict level) or with the conflict between the entire group and that individual (ie, individual-group conflict level). These two cases are easily illustrated by the statements like "I am in conflict with this person because my entire group / my subgroup is in conflict with him/her..."

\section{Practical implications}

Multidimensional model of intragroup conflict that guided this research broadens our understanding of this phenomenon as it goes well beyond more traditional framework for studying conflicts in work groups that limits focus of attention predominantly on interpersonal conflict (ie, between individual group members or between an individual worker and the group leader). From the applied perspective, associations observed in our study could predict levels and types of conflicts in real work groups based on the assessment of these groups' formal characteristics. Based on that model and findings of the current study practitioners (administrators, consultants, etc), intragroup conflicts (whenever it is possible) could be managed more efficiently by carefully adjusting various formal group characteristics.

\section{Conclusion}

When studying connections between formal quantitative group characteristics and parameters of intragroup conflicts, it is imperative to take into account all conflict levels - interpersonal, individual-subgroup (sometimes, in the literature referred to as "micro-conflict"), and individual-group (also called just "group conflict") - of both the types (ie, subjectoriented and activity-oriented). Group size is negatively associated with the SOC-IS and serves as an intermediary variable in the relationships between several formal quantita- 
tive group characteristics and conflict parameters. The latter case was quite evident in large-size groups but was absent (at least, at the level of statistical significance) in small-size groups. Out of all group characteristics, explored in the study, only group composition by age is not connected to any of the conflict parameters. In general, group characteristics are found to be stronger predictors of the conflict parameters in large-size groups - that is, it seems that an increase in group size amplifies the influence group characteristics have on conflict parameters.

In concluding remarks, we suggest that the multidimensional model introduced here opens new horizons in research of connections between conflict parameters and formal quantitative and psychological group characteristics and group effectiveness. Applying this knowledge to practice will allow for developing better means of conflict management and positively affect group functioning.

\section{Acknowledgment}

This research was implemented with the financial support from the Southern Federal University (Rostov-on-Don, Russia).

\section{Disclosure}

The authors report no conflicts of interest in this work.

\section{References}

1. Dontsov AI, Polozova TA. Problem of objective determinants of the interpersonal conflict in group. Bulletin of the Moscow University. Series 14. Psychology. 1977;4:23-32.

2. Shakurov RH, Alishev BS. Causes of the conflicts in pedagogical collective and ways of their regulation. Voprosy Psikhologi. 1986;6:67-76.

3. Sidorenkov AV. Small Group and Informal Subgroups: Microgroup Theory. Rostov-on-Don: Southern Federal University; 2010.

4. Sidorenkov AV. Intragroup Contradictions, Conflicts and Effectiveness of Groups in the Organization. Rostov-on-Don: Mini Taip; 2017.

5. Grishina NV. Social-psychological conflicts and improvement of relationship in work collective. In: Shorokhova EV, editor. Social-Psychological Problems of Work Collective. Moscow: Nauka; 1983:115-123.

6. Kotlyar I, Karakowsky L. Leading conflict? Linkages between leader behaviors and group conflict. Small Group Res. 2006;37(4):377-403.

7. Sullivan PJ, Feltz DL. The relationship between intrateam conflict and cohesion within hockey teams. Small Group Res. 2001;32(3): 342-355.

8. Peterson RS, Behfar KJ. The dynamic relationship between performance feedback, trust, and conflict in groups: A longitudinal study. Organ Behav Hum Decis Process. 2003;92(1-2):102-112.

9. Amason AC, Sapienza HJ. The effects of top management team size and interaction norms on cognitive and affective conflict. $J$ Manage. 1997;23(4):495-516.

10. Jehn KA. A Multimethod Examination of the Benefits and Detriments of Intragroup Conflict. Adm Sci Q. 1995;40(2):256-282.

11. Jehn KA, Bendersky C. Intragroup conflict in organizations: a contingency perspective on the conflict-outcome relationship. Res Organ Behav. 2003;25:187-242.
12. Choi JN, Sy T. Group-level organizational citizenship behavior: Effects of demographic faultlines and conflict in small work groups. Journal of Organizational Behavior. 2010;31:1032-1054.

13. Grissom JA. The determinants of conflict on governing boards in public organizations: The case of California school boards. Journal of Public Administration Research and Theory. 2010;20(3):601-627.

14. Jehn KA, Northcraft GB, Neale MA. Why differences make a difference: A field study of diversity, conflict, and performance in workgroups. $\mathrm{Adm}$ Sci Q. 1999;44(4):741-763.

15. Spell CS, Bezrukova K, Haar J, Spell C. Faultlines, fairness, and fighting: A justice perspective on conflict in diverse groups. Small Group Res. 2011;42(3):309-340.

16. Hobman EV, Bordia P. The Role of Team Identification in the Dissimilarity-Conflict Relationship. Group Processes \& Intergroup Relations. 2006;9(4):483-507.

17. Topi H, Valacich JS, Rao MT. The effects of personality and media differences on the performance of dyads addressing a cognitive conflict task. Small Group Res. 2002;33(6):667-701.

18. Mohammed S, Angell LC. Surface- and deep-level diversity in workgroups: examining the moderating effects of team orientation and team process on relationship conflict. J Organ Behav. 2004;25(8):1015-1039.

19. Jehn KA, Chadwick C, Thatcher SMB. To agree or not to agree: The effects of value congruence, individual demographic dissimilarity, and conflict on workgroup outcomes. International Journal of Conflict Management. 1997;8(4):287-305.

20. Woehr DJ, Arciniega LM, Poling TL. Exploring the effects of value diversity on team effectiveness. J Bus Psychol. 2013;28(1):107-121.

21. Vodosek M. Intragroup conflict as a mediator between cultural diversity and work group outcomes. International Journal of Conflict Management. 2007;18(4):345-375.

22. Pelled LH, Eisenhardt KM, Xin KR. Exploring the black box: An analysis of work group diversity, conflict, and performance. Adm Sci Q. 1999;44(1):1-2.

23. Randel AE. Identity salience: a moderator of the relationship between group gender composition and work group conflict. J Organ Behav. 2002;23(6):749-766.

24. Behfar KJ, Mannix EA, Peterson RS, Trochim WM. Conflict in small groups: The meaning and consequences of process conflict. Small Group Res. 2011;42(2):127-176.

25. Choi K, Cho B. Competing hypotheses analyses of the associations between group task conflict and group relationship conflict. J Organ Behav. 2011;32(8):1106-1126.

26. Greer LL, Jehn KA, Mannix EA. Conflict transformation: A longitudinal investigation of the relationships between different types of intragroup conflict and the moderating role of conflict resolution. Small Group Research. 2008;39(3):278-302.

27. Jehn KA, Greer L, Levine S, Szulanski G. The effects of conflict types, dimensions, and emergent states on group outcomes. Group Decision and Negotiation. 2008;17(6):465-495.

28. Sidorenkov AV, Lokteva EA, Mkrtchyan AA. Instruments for types of interpersonal contradictions and conflicts in small groups study. Psikhologicheskii Zhurnal. 2014;35(2):103-117.

29. Kerwin S, Doherty A, Harman A. "It's not conflict, it's differences of opinion": An in-depth examination of conflict in nonprofit boards. Small Group Research. 2011;42(5):562-594.

30. Hamm-Kerwin S, Doherty A. Intragroup Conflict in Nonprofit Sport Boards. Journal of Sport Management. 2010;24(3):245-271.

31. Sidorenkov AV. The development of tools for studying group and microgroup conflicts in groups of employees. Rossiyskiy Psikhologicheskiy Zhurnal. 2016;13(3):89-106.

32. Sidorenkov AV, Pavlenko RV. GROUP PROFILE computer technique: A tool for complex study of small groups. SAGE Open. 2015;5(1):1-13.

33. Blau PM. Inequality and Heterogeneity: A Primitive Theory of Social Structure. New York, NY: Free Press; 1997.

34. Bayazit M, Mannix EA. Should I stay or should I go? Predicting team members' intent to remain in the team. Small Group Research. 2003;34(3):290-321. 
Psychology Research and Behavior Management is an international, peerreviewed, open access journal focusing on the science of psychology and its application in behavior management to develop improved outcomes in the clinical, educational, sports and business arenas. Specific topics covered in the journal include: Neuroscience, memory and decision making; Behavior
Submit your manuscript here: https://www.dovepress.com/psychology-research-and-behavior-management-journal 